\title{
Goodwill survey suggests 'a return to normality'
}

The latest results published from the National Association of Specialist Dental Accountants and Lawyers (NASDAL) Goodwill Survey statistics suggests there may be a return to normality in the offing.

The survey covers the quarter ending 31 July 2021 and includes data on valuations as well as deals completed (i.e., practices bought or sold by NASDAL members' clients in the period).

The quarter saw big jumps both in those deals completed and valuations. In terms of deals done, goodwill as a percentage of fee income in the quarter across all types of practice averaged $144 \%$ of gross fees - that was a significant leap from $128 \%$ in the quarter to $31^{\text {st }}$ April 2021. NHS practice goodwill bounced back with practice goodwill at $161 \%$ of gross fees - up from $146 \%$ in the previous period.

Private practices' goodwill values saw a big increase - up to $133 \%$ of gross fees from $110 \%$ of gross fees in the previous quarter. Mixed practices reduced slightly with values of $145 \%$ of gross fees from $156 \%$ of gross fees last time.

Alan Suggett, specialist dental accountant and partner in UNW LLP who compiles the goodwill survey, commented: 'In my commentary on the last results, I did say that I was surprised to see big drops in goodwill values and that it had not been my subjective experience. As with all statistics, there can be anomalies.

'It seems that the figures from this latest quarter have borne that out. Why did last quarter's figures occur? I would be speculating but it could be that there was a backlog of discounted deals that were delayed due to COVID-19 and they all went through in the one quarter.

'Certainly as we move forward, NASDAL members are reporting that the market is robust and that sale prices are not being reduced and are reaching their full potential.'

The goodwill figures are collated from accountant and lawyer members of NASDAL in order to give a useful guide to the practice sales market.

\section{NASDAL QUARTERLY GOODWILL SURVEYS}

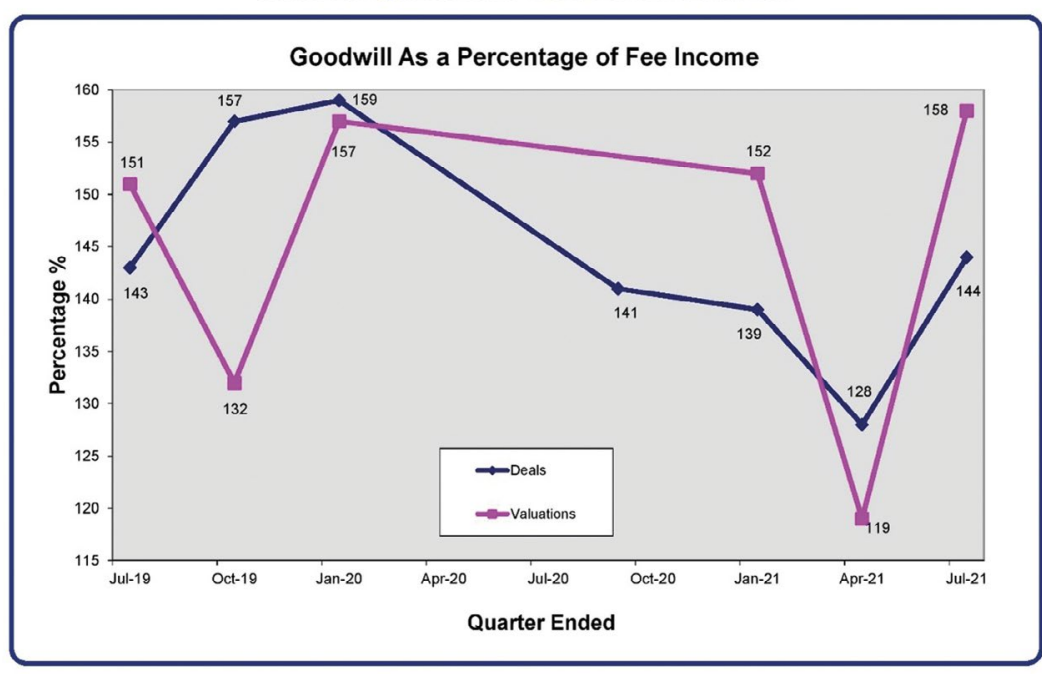

\section{Child asylum seekers: dental age check plan}

\section{dropped, but key questions remain}

On 6 April 2021 BDJ In Practice published in hardcopy and online an article entitled 'Principle 8 - Surviving your professional duty'. We hereby retract the article and confirm that it was published without the content being confirmed by, or a response sought from, the practice and practitioners asserted to be referred to therein. $B D J$ In Practice takes no position with respect of the accuracy of the contents and this retraction is by agreement with the practice and the practitioners asserted to be referred to therein. This article has been removed from the online version of $B D J$ In Practice.
The British Dental Association has welcomed reports the Home Office has reconsidered plans to introduce the use of dental $x$-rays to determine age in asylum cases. The Association has been campaigning against the rollout of dental age checks for migrants, working closely with the Refugee Council, alongside other healthcare bodies and opposition health and home teams.

It is expected government amendments to the Nationality and Borders Bill will still give significant latitude to the Home Office to define in due course what constitutes 'robust' and 'scientific methods' of age assessment. On that basis the BDA will continue to seek amendments to the Bill to rule out radiographic tests.

The Association has vigorously opposed the use of dental X-rays to determine whether asylum seekers have reached the age of 18 , stressing they are an inaccurate method for assessing age. The BDA also believes that it is inappropriate and unethical to subject people to radiation when there is no health benefit for them. X-rays taken for a clinically justified reason must not be used for another purpose without the patient's informed consent and must be carried out without coercion and in full knowledge of how the radiograph will be used and by whom.

British Dental Association Chair Eddie Crouch said: 'It's welcome news that Ministers appear to have ruled out dental checks on migrants that fail basic tests on accuracy and ethics.

'However, new laws will still give the government power to define what constitutes a 'robust' measure of age. Dentists do not want to see pseudoscience make a return via the back door.' 